\title{
Water-Transmitted Fungi Are Involved in Degradation of Concrete Drinking Water Storage Tanks
}

\author{
Monika Novak Babič * (D) and Nina Gunde-Cimerman (DD \\ Department of Biology, Biotechnical Faculty, University of Ljubljana, SI-1000 Ljubljana, Slovenia; \\ nina.gunde-cimerman@bf.uni-lj.si \\ * Correspondence: monika.novakbabic@bf.uni-lj.si
}

\begin{abstract}
Global warming, globalization, industrialization, and the rapidly growing population at present increasingly affect the production of safe drinking water. In combination with sustainable bio-based or recycled materials, used for water distribution systems, these factors promote emerging pathogens, including fungi. They can proliferate in oligotrophic water systems, affect the disinfection process, degrade building materials, and cause diseases in humans. In this study, we explored fungalbased degradation of modern concrete water storage tanks and the presence of fungi in chlorinated drinking water at the entrance and exit of the tanks. The degradation potential of isolated 52 fungal strains and their growth at different oligotrophic conditions was tested in vitro. Forty percent of strains grew at extremely oligotrophic conditions, and 50\% classified as aerophilic. Two-thirds of tested strains produced acids, with Penicillium strains as the best producers. Only $29.7 \%$ of the strains were able to grow at $37^{\circ} \mathrm{C}$, and none of them was isolated from drinking water at consumers taps. Although not yet part of the guidelines for building materials in contact with drinking water, fungi should be taken into consideration in case of visible degradation. Their number of consumers' endpoints should be checked to exclude possible health risks for consumers.
\end{abstract}

Keywords: degradation; chlorination; drinking water; environmental factors; fungal contaminants; growth of fungi; materials in contact with drinking water; water storage tanks

Gunde-Cimerman, N.

Water-Transmitted Fungi Are

Involved in Degradation of Concrete Drinking Water Storage Tanks. Microorganisms 2021, 9, 160. https://doi.org/10.3390/ microorganisms 9010160

Received: 11 November 2020 Accepted: 11 January 2021 Published: 12 January 2021

Publisher's Note: MDPI stays neutral with regard to jurisdictional clai$\mathrm{ms}$ in published maps and institutional affiliations.

Copyright: $(2021$ by the authors. Licensee MDPI, Basel, Switzerland. This article is an open access article distributed under the terms and conditions of the Creative Commons Attribution (CC BY) license (https:// creativecommons.org/licenses/by/ $4.0 /)$.

\section{Introduction}

During the 19th and 20th centuries, humanity was driven by modern technical development and rapid urbanization. Since water is essential for life and its presence was regularly needed also for industrial development, most urban centres evolved next to the main water sources. This led to water pollution and caused many disease outbreaks [1]. Increasing knowledge in the fields of medicine, microbiology and chemistry established the connection between the presence of pathogens in water with diseases and implemented water cleaning procedures and the necessity for water quality monitoring [2]. These procedures prevented many deaths and contributed to a prolonged life span. Nowadays human population faces different threats. The world is quickly changing due to global warming [3], increasing globalisation, industrialisation, and growing population. Care for enough safe drinking water remains one of humanity's most important global goals [4].

The current legislation includes the monitoring of many microbes, particularly the causative agents of gastrointestinal illnesses, however, listed global changes also promote the growth of other microorganisms, recognized as emerging pathogens, but not yet included in drinking water regulations $[5,6]$. Among them, the members of the fungal kingdom stepped into the forefront [7].

The presence of fungi in water has been known for a long time. Usually, the fungi have been connected to changes in taste, color, and odor of water $[4,8,9]$, but lately, they have become increasingly recognized as emerging opportunistic pathogens, raising health concerns [4]. Mixed fungal bacterial biofilms often cause problems in industries, depending on the water sources used [8]. Nevertheless, there is still no uniform legislation on 
the building materials used in safe drinking water production. These choices depend on the country's authorities and industrial financial budget $[10,11]$. Another aspect is the sustainable use of water and energy, that in combination with bio-based or recycled materials, often promotes the growth of sturdy fungal biofilms [12,13]. The World Health Organisation (WHO) reported and associated with contamination of wet materials species Aspergillus flavus, A. versicolor, Cladosporium cladosporioides, C. herbarum, C. sphaerospermum, Mucor circinelloides and Rhizopus oryzae [14]. Moreover, species of the genera Acremonium, Alternaria, Candida, Debaryomyces, Fusarium, Kluyveromyces, Meyerozyma, Rhodotorula, Penicillium, Stachybotrys and Trichoderma were reported as biodegraders of materials used for water transport $[15,16]$. The most commonly isolated fungi on the damp walls covered with plaster, wallpaper, and gypsum were Acremonium spp., Penicillium chrysogenum, Stachybotrys spp., Ulocladium spp., and Phoma spp. On the contrary, concrete coatings were more likely colonized by the fungi Sporothrix spp., Chaetomium spp., and Penicillium spp. In addition, Aspergillus fumigatus, A. melleus, A. niger, A. ochraceus, Chaetomium spp., Mucor racemosus, and $M$. spinosus [15] are often present on the concrete, final layers and adhesives (cork, linoleum and glue). The ubiquitary present fungal genus, regardless of the type of damaged material, was Penicillium [15]. Plastic materials, silicone, and rubber are colonized by Candida spp., Cystobasidium sloofiae, Magnusiomyces capitatus, Meyerozyma guilliermondii, Naganishia spp., Rhodotorula mucilaginosa, and melanized black yeasts Phialophora spp. and Rhinocladiella similis [4]. Biodegradation and deterioration of these materials are due to fungal production of organic acids $[17,18]$, precipitation of minerals, leaching, and after extended periods of fungal growth also mechanical degradation (e.g., scaling, peeling, cracking) of the material [19]. These changes do not only cause water leakage and expenses due to clogging; they also negatively affect chlorination, taste, color, and odor of water [8].

The aim of the present study was to determine the presence, abundance, and diversity of fungi in chlorinated water entering 1.5 years old concrete water storage tanks already showing degradation, seen as local scaling and discoloration. We isolated and identified fungi actively involved in the colonization and degradation of ceilings in these tanks. Additionally, we followed the possible transmission of these fungi in the water distribution system, to the tap water end, in order to assess their potential effect on consumers' health.

\section{Materials and Methods}

2.1. Sampling of Drinking Water and Materials in Contact with Drinking Water, and Cultivation of Fungal Strains

Samples of $1.5 \mathrm{~L}$ of water were taken from 8 sampling points (Figure 1) in sterile containers as described by the standard SIST ISO 5667-5:2007. Samples were transported to the laboratory and processed immediately. Physico-chemical parameters of water samples were measured as required in Drinking Water Directive (98/83/EC) [5] at Komunala Novo mesto d.o.o., Slovenia, by trained personnel. Parameters included temperatures of water and air, concentrations of disinfectant, electric conductivity, $\mathrm{pH}$, color, smell, taste, turbidity, and visible presence of sediment.

For analysis of fungal presence, aliquots of $100 \mathrm{~mL}$ were filtered through $0.45 \mathrm{~mm}$ membrane filters (Merck, Millipore, Darmstadt, Germany). Filters were placed on solid media Dichloran Rose Bengal Agar (DRBC; Oxoid Ltd., Oslo, Norway) and Malt Extract Agar with the addition of chloramphenicol $(\mathrm{MEA}+\mathrm{Ch})$ to prevent bacterial growth. After visible growth of fungi, colonies on 10 aliquots of $100 \mathrm{~mL}$ were counted and colony-forming units per liter (CFU/L) were calculated.

Samples from concrete and metal materials in contact with drinking water were taken from water storage tanks in Lutrško selo and Gorenja vas (both Novo mesto, Slovenia) by rubbing $1 \mathrm{~cm}^{2}$ of area with sterile cotton swabs (Figure 1), soaked in sterile saline solution. Swab samples were inoculated in duplicates by rubbing the whole area of the DRBC and MEA+Ch media. 


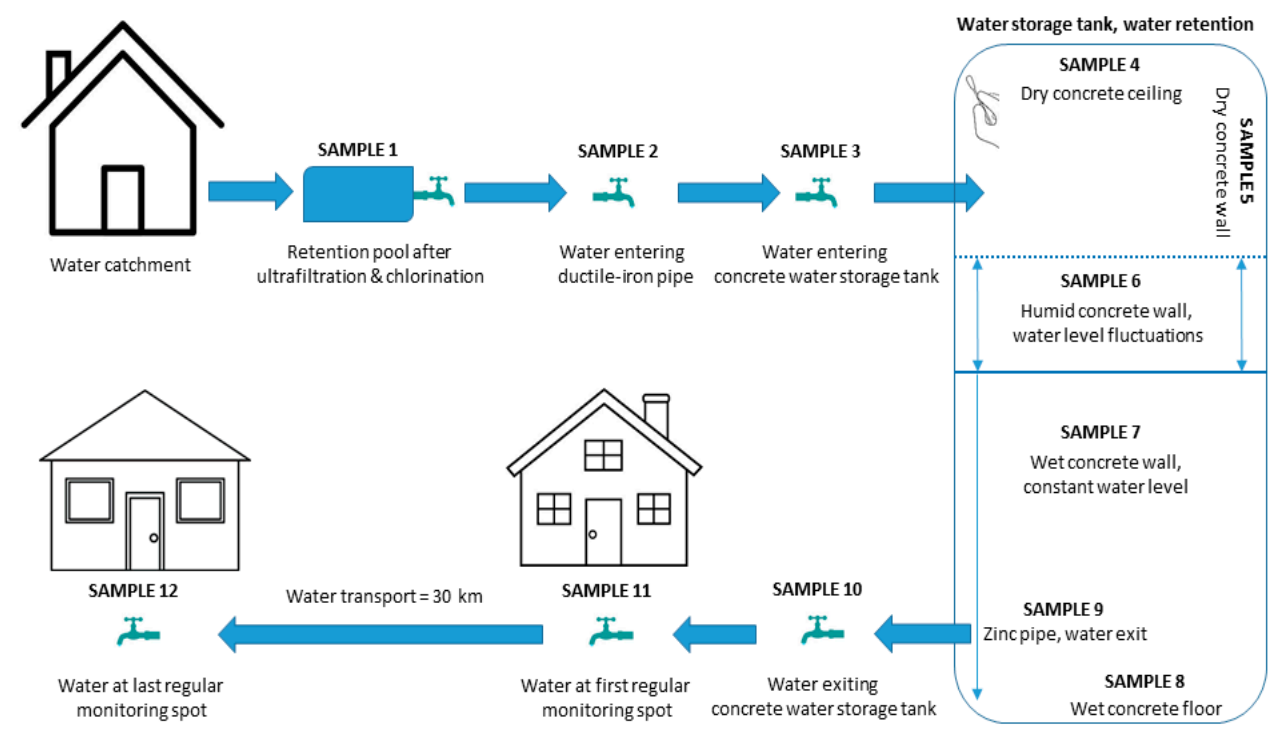

Figure 1. Sampling spots throughout water distribution system and inside concrete water storage tanks. Water samples are indicated as Sample-1, to -3, and Sample-10 to -12. Thick blue arrows indicate water flow. Samples inside the two concrete tanks that were taken by swabbing the surface are indicated as Sample- 4 to -9 . Thin blue arrows indicate water level as fluctuating or permanent.

All plates were incubated at $25^{\circ} \mathrm{C}$ and $37^{\circ} \mathrm{C}$ for 5 to 7 days. After visible growth of fungi, colonies were counted and colony-forming units (CFU/L and $\mathrm{CFU} / \mathrm{cm}^{2}$ ) were calculated. All morphologically different strains were transferred to fresh Malt Extract Agar (MEA) plates and later permanently stored in the Ex Culture Collection of the Infrastructural Centre Mycosmo, MRIC UL, Slovenia (http:/ / www.ex-genebank.com/), at the Department of Biology, Biotechnical Faculty, University of Ljubljana.

\subsection{Extraction of Genomic DNA and Identification of Fungi}

All cultures were grown on MEA prior to the extraction of the genomic DNA. DNA of filamentous fungi was extracted from 5 days old cultures by mechanical lysis of mycelia as recommended by Van den Ende and de Hoog [20]. DNA from 3 days old yeast cultures was extracted with PrepMan Ultra reagent (Applied Biosystems, Foster City, USA) according to the manufacturer's instructions. Obtained DNA samples were stored at $-20{ }^{\circ} \mathrm{C}$ till further use.

Depending on their morphological characterization, complete identification of filamentous fungi based either on the rDNA nucleotide sequence analyses of the whole internal transcribed spacer region (ITS: ITS1, 5.8S rDNA and ITS 2), partial beta-tubulin gene exons and introns $(b e n A)$, or the partial actin gene (act). Yeasts were identified by their large subunit ribosomal DNA (LSU) sequence (partial 28S rDNA, D1/D2 domains). Amplification and sequencing were carried out with primer pairs ITS5 and ITS4 [21], Bt2a and Bt2b [22], ACT-512F and ACT-783R [23], or NL1 and NL4 [24]. Sequences were obtained at Microsynth AG, Austria and assembled by FinchTV 1.4 (Geospiza, PerkinElmer, Inc., Seattle, USA). The alignments were adjusted using Molecular Evolutionary Genetics Analysis (MEGA) software version 7.0 [25] and identified with the BLAST algorithm on the NCBI web page [26]. Final identification was supported by taxonomically important databases such as Westerdijk Fungal Biodiversity Institute (Utrecht, the Netherlands) and Index Fungorum (www.indexfungorum.org). The sequences of representative strains used in the study were deposited in the GenBank database (NCBI).

\subsection{Fungal Growth under Oligotrophic Conditions and Their Biodegradation Potential}

Based on their taxonomy and location of isolation, 52 different strains were selected for further analysis. They were tested at different environmental conditions, to determine 
whether water and materials serve only as vectors for transmission or promoted fungal growth. Fungal adaptation to oligotrophic conditions was tested on 100-times diluted Yeast Nitrogen Base (YNB) solid medium and $2 \%$ water agar medium (WA).

In order to check their biodegradation and biodeterioration potential calcium carbonate $\left(\mathrm{CaCO}_{3}\right)$ agar plates [27] were used. Additionally, changes in $\mathrm{pH}$ were measured after incubation in liquid medium with neutral pH [28] using Seven Compact S210 (Mettler Toledo, Switzerland). Growth of fungi in real-life conditions was tested on a commercial product used for concrete coatings (Xypex Concentrate, XYPEX CE s.r.o.), consisting of portland cement (30-60\%), alkaline earth compounds (10-30\%), silica sand (30-60\%) and calcium aluminates $(<10 \%)$. Xypex plates were prepared according to the manufacturer's instructions and wetted with $5 \mathrm{~mL}$ of sterile water prior to use.

Fungal cell suspensions were prepared from 3-5 days old cultures in a sterile saline solution and adjusted to $\sim 1.0 \times 10^{8} \mathrm{CFU} / \mathrm{mL}$. Ten microliters of the suspensions were inoculated on all media and incubated at $15^{\circ} \mathrm{C}$ for 1 month. One series of inoculated YNB medium was used for testing the ability of strains to grow at human body temperature $\left(37^{\circ} \mathrm{C}, 1\right.$ month). Xypex Concentrate plates were incubated at $15^{\circ} \mathrm{C}$ up to 3 months. After incubation, growth of fungi was checked and described as very good $(+++)$ when mycelium covered $>70 \%$ of the plate, good $(++;$ mycelium covered $41-70 \%$ of the plate), weak (+; mycelium covered $20-40 \%$ of the plate), poor $(-/+;$ mycelium covered $<20 \%$ of the plate) or none (-; no growth was observed).

\section{Results}

\subsection{Fungi Are Present at Every Stage of Drinking Water Preparation}

Drinking water was sampled at eight different locations: from a pool after ultrafiltration (1), from a pipe at the beginning of transport toward water storage tanks (2), at the entrance of water storage tanks ( $3 a$ and $3 b)$, at the exit of water storage tanks (4a and $4 \mathrm{~b}$ ), at the first sampling point for water monitoring (5), and at the last sampling point for regular water monitoring (6) (Figure 1). All tested physico-chemical parameters of water samples were in normal range set by Drinking Water Directive (98/83/EC), e.g., water hardness $=15.2 \mathrm{~N}$ (medium hard water), electrical conductivity at $20{ }^{\circ} \mathrm{C}=423-430 \mu \mathrm{S} / \mathrm{cm}$, total organic carbon (TOC $<0.3 \mathrm{mg} / \mathrm{L}$ ), Ammonium $<0.01 \mathrm{mg} / \mathrm{L}$, Nitrite $<0.001 \mathrm{mg} / \mathrm{L}$, Nitrate $=3.92-4.53 \mathrm{mg} / \mathrm{L}$, Manganese $<0.1-0.14 \mu \mathrm{g} / \mathrm{L}$, Iron $<40 \mu \mathrm{g} / \mathrm{L}$, Aluminum $=5.5-$ $6.1 \mu \mathrm{g} / \mathrm{L}$, Arsenic $=0.49-0.54 \mu \mathrm{g} / \mathrm{L}$, Copper $=0.0035-0.0078 \mathrm{mg} / \mathrm{L}$, Cadmium $<0.02 \mu \mathrm{g} / \mathrm{L}$, Chromium $=0.54-0.57 \mu \mathrm{g} / \mathrm{L}$, Nickel $<0.1 \mu \mathrm{g} / \mathrm{L}$, and Lead $=0.27-0.34 \mu \mathrm{g} / \mathrm{L}$. The $\mathrm{pH}$, measured at temperatures $20-21^{\circ} \mathrm{C}$ was slightly alkaline, between 7.3 and 7.5. Additionally, chlorination performed with gaseous chlorine $\left(\mathrm{Cl}_{2}\right)$ did not show any discrepancies, with amounts of residual chlorine within the recommended range at all eight sampling points (between 0.15 and $0.30 \mathrm{mg} / \mathrm{L}$ ).

Fungi were isolated from all water samples (Table 1). The most frequently isolated genus was Cladosporium, detected in four out of eight sampling locations (50\%). One-third of the samples were positive for filamentous fungi of the genera Acremonium, Exophiala, Gloeotinia, Neopyrenochaeta, and Penicillium, while yeasts were detected only sporadically. Some fungi were not detected throughout the water preparation process. For instance, water from the retention pool yielded after ultrafiltration 146 CFU/L, 143 of them were identified as Exophiala cancerae. Nevertheless, this species was completely absent at later stages that followed water chlorination. The number of fungi in chlorinated drinking water was the highest before entering the main pipe system toward water storage tanks and at the immediate entrance to water storage tanks (both uncountable; $>330 \mathrm{CFU} / \mathrm{L}$ ). The most common fungus in water before entering the pipe system was Acremonium sclerotigenum (160 CFU/L), while Gloeotinia sp. dominated in samples just before entering the water storage tanks (> $330 \mathrm{CFU} / \mathrm{L}$ ) and at the exit point of the tanks (153 out of $226 \mathrm{CFU} / \mathrm{L}$ ). Numbers lowered with the distance and time of water transportation. For instance, species of Cladosporium and Penicillium were present in water entering and exiting the storage tanks, while only Cladosporium was detected also at the first consumers' tap sampling 
point. The lowest number of fungi was detected in the samples at the first and the last regular monitoring spot at consumers' taps (both $73 \mathrm{CFU} / \mathrm{L}$ ). Cadophora malorum was with $30 \mathrm{CFU} / \mathrm{L}$ the most common fungus at the first consumers' tap collection point, and Aaosphaeria arxii $(60 \mathrm{CFU} / \mathrm{L})$ was the most common species after $30 \mathrm{~km}$ of water flow at the last consumers' tap collection point (Table 1 and Figure 2).

\subsection{Number and Diversity of Fungi Inside Two Water Storage Tanks}

Both concrete water storage tanks were filled with drinking water of the same origin, following the same preparation procedure. Although only 1.5 years old, both showed local degradations like cracks and peeling. Additionally, walls below the constant water level changed the color from grey to ochre. At some points growth of visible fungal mycelia was observed (Figure 3). All samples from the surfaces of water storage tanks were positive for fungi and together yielded 23 isolates. Their numbers were the highest on a dry ceiling (Samples-4a and $4 \mathrm{~b}$ ), locally covered with condensate of water drops. There several species (Akanthomyces muscarius, Aspergillus protuberus, Cladosporium sphaerospermum, Musicillium elettariae and Sarocladium kiliense) co-occurred in more than $330 \mathrm{CFU} / \mathrm{cm}^{2}$ (Table 1). An uncountable number of fungal colonies per $\mathrm{cm}^{2}$ was observed also on humid walls of water storage tanks, where water level varies depending on the production/consumption ratio of water. Contrary to the dry ceiling with high numbers and diversity of fungi, samples taken from humid walls yielded monoculture of Furcasterigmium furcatum. This species was present also on dry (Samples-5a and 5b) and completely wet walls (Samples-7a and $7 \mathrm{~b}$ ) and likely grew also on concrete under constant water level. Furcasterigmium often co-existed with Sarocladium kiliense, also present on wet walls under constant water level, and on the surface of the metal pipe for water exit inside the tanks. The least contaminated part of the concrete water storage tanks was the bottom, with only few colonies of conidiogenic fungi per $\mathrm{cm}^{2}$. The water pressure on the bottom is higher and oxygen level is lower in comparison to upper sampled locations (Table 1).

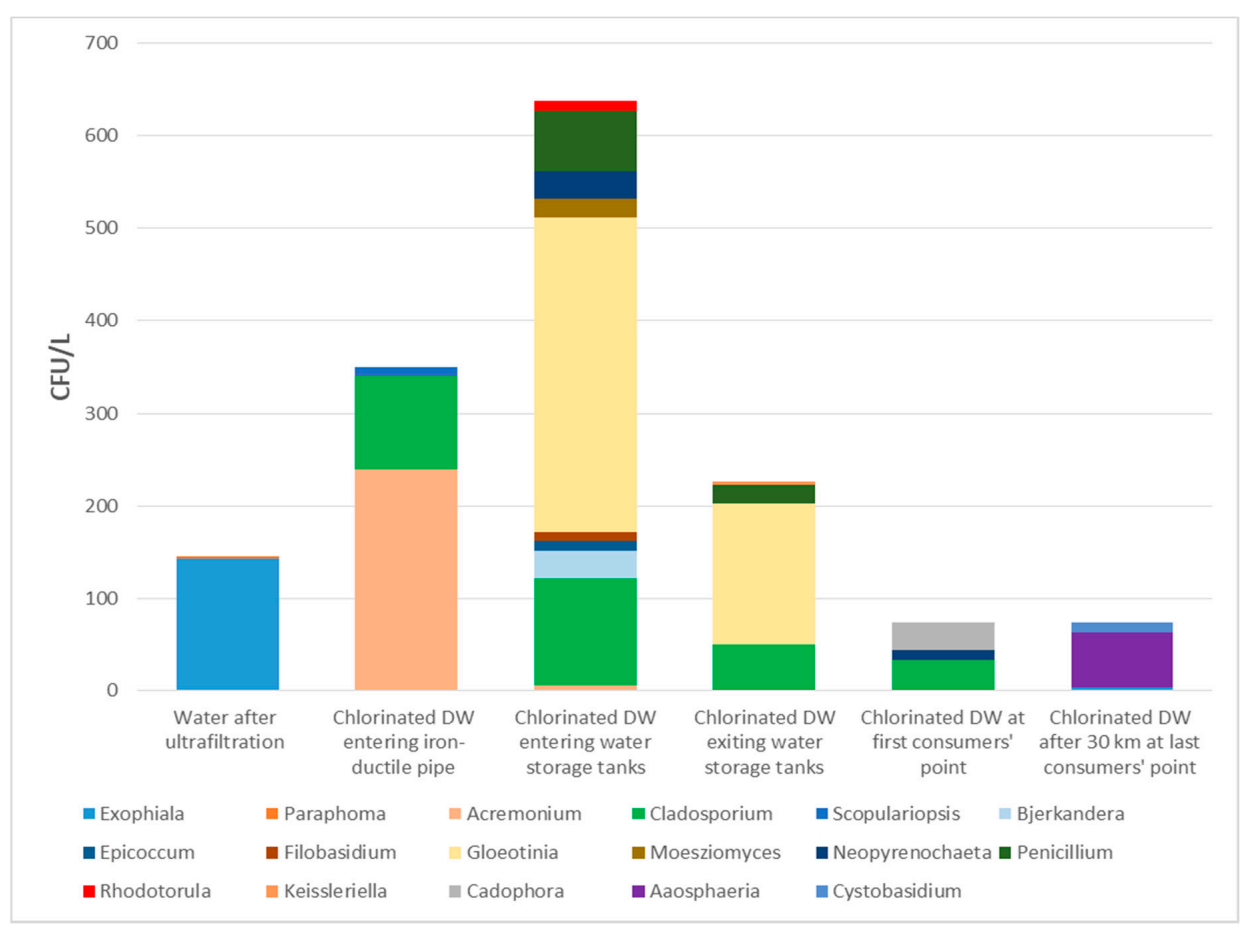

Figure 2. Presence and diversity of fungal genera throughout water distribution network. Drinking water (DW) was sampled at eight distant locations. Both, the diversity and the numbers (CFU/L) were highest at the point of entrance into the concrete water storage tanks and the lowest at consumers' endpoints (taps), indicating sensitivity to chlorine under prolonged exposure time. The genus Cladosporium was the most frequently isolated (four out of eight sampling spots). 
Table 1. Number and diversity of fungi isolated from drinking water through distribution network and from concrete water storage tanks.

\begin{tabular}{|c|c|c|c|c|c|c|}
\hline Sample Number & Description & $\begin{array}{l}\text { Total Number of } \\
\text { Fungal Colonies }\end{array}$ & $\begin{array}{c}\text { Number of Colonies } \\
\text { per Species }\end{array}$ & Genus & Species & EXF- No * \\
\hline \multirow{2}{*}{ Sample -1} & \multirow{2}{*}{$\begin{array}{c}\text { Water from retention pool after } \\
\text { ultrafiltration }\end{array}$} & \multirow{2}{*}{$146 \mathrm{CFU} / \mathrm{L}$} & $143^{+} \mathrm{CFU} / \mathrm{L}$ & Exophiala & cancerae & 14903 \\
\hline & & & $3 \mathrm{CFU} / \mathrm{L}$ & Paraphoma & radicina & 14904 \\
\hline \multirow{4}{*}{ Sample-2 } & \multirow{4}{*}{$\begin{array}{l}\text { Chlorinated drinking water } \\
\text { entering iron-ductile pipe leading } \\
\text { toward water storage tanks }\end{array}$} & \multirow{4}{*}{350 CFU/L } & $80 \mathrm{CFU} / \mathrm{L}$ & Acremonium & charticola & 14755 \\
\hline & & & $160 \mathrm{CFU} / \mathrm{L}$ & Acremonium & sclerotigenum & $14749,14750,14751,14791$ \\
\hline & & & $100 \mathrm{CFU} / \mathrm{L}$ & Cladosporium & sphaerospermum & 14744 \\
\hline & & & $10 \mathrm{CFU} / \mathrm{L}$ & Scopulariopsis & brumptii & 14743 \\
\hline \multirow{14}{*}{$\begin{array}{l}\text { Sample-3a (water storage tank 1) } \\
\text { and } 3 \mathrm{~b} \text { (water storage tank 2) }\end{array}$} & \multirow{14}{*}{$\begin{array}{l}\text { Chlorinated drinking water } \\
\text { entering water storage tanks }\end{array}$} & \multirow{14}{*}{$\begin{array}{c}\text { estimated as }>627 \\
\text { CFU } / \mathrm{L}\end{array}$} & $30 \mathrm{CFU} / \mathrm{L}$ & Bjerkandera & adusta & 14740 \\
\hline & & & $10 \mathrm{CFU} / \mathrm{L}$ & Cladosporium & allicinum & 14572 \\
\hline & & & $7 \mathrm{CFU} / \mathrm{L}$ & Cladosporium & cladosporioides & 14917 \\
\hline & & & $20 \mathrm{CFU} / \mathrm{L}$ & Cladosporium & halotolerans & 14567 \\
\hline & & & $70 \mathrm{CFU} / \mathrm{L}$ & Cladosporium & pseudocladosporioides & 14566,14575 \\
\hline & & & $10 \mathrm{CFU} / \mathrm{L}$ & Cladosporium & sphaerospermum & 14573 \\
\hline & & & $10 \mathrm{CFU} / \mathrm{L}$ & Epicoccum & nigrum & 14736 \\
\hline & & & $10 \mathrm{CFU} / \mathrm{L}$ & Filobasidium & uniguttulatum & 14741 \\
\hline & & & $>330 \mathrm{CFU} / \mathrm{L}$ & Gloeotinia & sp. & $14568,14738,14739$ \\
\hline & & & $30 \mathrm{CFU} / \mathrm{L}$ & Neopyrenochaeta & fragariae & 14737,14754 \\
\hline & & & $35 \mathrm{CFU} / \mathrm{L}$ & Penicillium & brevicompactum & 14918 \\
\hline & & & $10 \mathrm{CFU} / \mathrm{L}$ & Penicillium & glabrum & 14569,14570 \\
\hline & & & $20 \mathrm{CFU} / \mathrm{L}$ & Penicillium & verhagenii & 14571 \\
\hline & & & $10 \mathrm{CFU} / \mathrm{L}$ & Rhodotorula & mucilaginosa & 14574 \\
\hline \multirow{5}{*}{$\begin{array}{l}\text { Sample-4a (water storage tank 1) } \\
\text { and } 4 \mathrm{~b} \text { (water storage tank 2) }\end{array}$} & \multirow{5}{*}{$\begin{array}{c}\text { Dry concrete ceiling inside water } \\
\text { storage tanks }\end{array}$} & \multirow{5}{*}{$>330 \mathrm{CFU} / \mathrm{cm}^{2}$} & $90 \mathrm{CFU} / \mathrm{cm}^{2}$ & Akanthomyces & muscarius & 14589 \\
\hline & & & $>330 \mathrm{CFU} / \mathrm{cm}^{2}$ & Aspergillus & protuberus & 14928,14929 \\
\hline & & & $>330 \mathrm{CFU} / \mathrm{cm}^{2}$ & Cladosporium & sphaerospermum & 14927 \\
\hline & & & $>330 \mathrm{CFU} / \mathrm{cm}^{2}$ & Musicillium & elettariae & 14931 \\
\hline & & & $>330 \mathrm{CFU} / \mathrm{cm}^{2}$ & Sarocladium & kiliense & 14930 \\
\hline \multirow{2}{*}{$\begin{array}{l}\text { Sample-5a (water storage tank } 1 \text { ) } \\
\text { and } 5 \mathrm{~b} \text { (water storage tank 2) }\end{array}$} & \multirow{2}{*}{$\begin{array}{l}\text { Dry concrete wall inside water } \\
\text { storage tanks }\end{array}$} & \multirow{2}{*}{$11 \mathrm{CFU} / \mathrm{cm}^{2}$} & $5 \mathrm{CFU} / \mathrm{cm}^{2}$ & Furcasterigmium & furcatum & 14586,14587 \\
\hline & & & $6 \mathrm{CFU} / \mathrm{cm}^{2}$ & Sarocladium & kiliense & 14585 \\
\hline $\begin{array}{l}\text { Sample-6a (water storage tank } 1 \text { ) } \\
\text { and } 6 \mathrm{~b} \text { (water storage tank 2) }\end{array}$ & $\begin{array}{l}\text { Humid concrete wall inside water } \\
\text { storage tanks }\end{array}$ & $>330 \mathrm{CFU} / \mathrm{cm}^{2}$ & $>330 \mathrm{CFU} / \mathrm{cm}^{2}$ & Furcasterigmium & furcatum & 14926 \\
\hline
\end{tabular}


Table 1. Cont

\begin{tabular}{|c|c|c|c|c|c|c|}
\hline Sample Number & Description & $\begin{array}{l}\text { Total Number of } \\
\text { Fungal Colonies }\end{array}$ & $\begin{array}{c}\text { Number of Colonies } \\
\text { per Species }\end{array}$ & Genus & Species & EXF- No* \\
\hline $\begin{array}{l}\text { Sample-7a (water storage tank } 1) \\
\text { and } 7 \mathrm{~b} \text { (water storage tank } 2 \text { ) }\end{array}$ & $\begin{array}{l}\text { Wet concrete wall inside water } \\
\text { storage tanks }\end{array}$ & $94 \mathrm{CFU} / \mathrm{cm}^{2}$ & $\begin{array}{c}56 \mathrm{CFU} / \mathrm{cm}^{2} \\
34 \mathrm{CFU} / \mathrm{cm}^{2} \\
4 \mathrm{CFU} / \mathrm{cm}^{2}\end{array}$ & $\begin{array}{l}\text { Furcasterigmium } \\
\text { Musicillium } \\
\text { Sarocladium }\end{array}$ & $\begin{array}{l}\text { furcatum } \\
\text { elettariae } \\
\text { kiliense }\end{array}$ & $\begin{array}{c}14583,14584 \\
14922 \\
14582\end{array}$ \\
\hline $\begin{array}{l}\text { Sample-8a (water storage tank } 1) \\
\text { and } 8 \mathrm{~b} \text { (water storage tank } 2)\end{array}$ & $\begin{array}{l}\text { Wet concrete bottom inside water } \\
\text { storage tanks }\end{array}$ & $9 \mathrm{CFU} / \mathrm{cm}^{2}$ & $\begin{array}{l}4 \mathrm{CFU} / \mathrm{cm}^{2} \\
3 \mathrm{CFU} / \mathrm{cm}^{2} \\
2 \mathrm{CFU} / \mathrm{cm}^{2}\end{array}$ & $\begin{array}{l}\text { Acremonium } \\
\text { Cladosporium } \\
\text { Trametes }\end{array}$ & $\begin{array}{l}\text { camptosporum } \\
\text { pseudocladosporioides } \\
\text { versicolor }\end{array}$ & $\begin{array}{l}14923 \\
14924 \\
14925\end{array}$ \\
\hline $\begin{array}{l}\text { Sample-10a (water storage tank } \\
\text { 1) and 10b (water storage tank 2) }\end{array}$ & $\begin{array}{l}\text { Chlorinated drinking water exiting } \\
\text { water storage tanks }\end{array}$ & $226 \mathrm{CFU} / \mathrm{L}$ & $\begin{array}{c}10 \mathrm{CFU} / \mathrm{L} \\
10 \mathrm{CFU} / \mathrm{L} \\
30 \mathrm{CFU} / \mathrm{L} \\
153 \mathrm{CFU} / \mathrm{L} \\
3 \mathrm{CFU} / \mathrm{L} \\
10 \mathrm{CFU} / \mathrm{L} \\
10 \mathrm{CFU} / \mathrm{L}\end{array}$ & $\begin{array}{c}\text { Cladosporium } \\
\text { Cladosporium } \\
\text { Cladosporium } \\
\text { Gloeotinia } \\
\text { Keissleriella } \\
\text { Penicillium } \\
\text { Penicillium }\end{array}$ & $\begin{array}{c}\text { allicinum } \\
\text { halotolerans } \\
\text { perangustum } \\
\text { sp. } \\
\text { caudata } \\
\text { bialowiezense } \\
\text { brevicompactum }\end{array}$ & $\begin{array}{c}14578 \\
14577 \\
14579 \\
14576,14580,14920 \\
14921 \\
14581 \\
14919\end{array}$ \\
\hline Sample-11 & $\begin{array}{l}\text { Chlorinated drinking water at the first } \\
\text { standard monitoring sampling point }\end{array}$ & $73 \mathrm{CFU} / \mathrm{L}$ & $\begin{array}{l}30 \mathrm{CFU} / \mathrm{L} \\
13 \mathrm{CFU} / \mathrm{L} \\
20 \mathrm{CFU} / \mathrm{L} \\
10 \mathrm{CFU} / \mathrm{L}\end{array}$ & $\begin{array}{l}\text { Cadophora } \\
\text { Cladosporium } \\
\text { Cladosporium } \\
\text { Neopyrenochaeta }\end{array}$ & $\begin{array}{l}\text { malorum } \\
\text { allicinum } \\
\text { pseudocladosporioides } \\
\text { acicola }\end{array}$ & $\begin{array}{l}14747 \\
14746 \\
14745 \\
14748\end{array}$ \\
\hline Sample-12 & $\begin{array}{l}\text { Chlorinated drinking water at the last } \\
\text { standard monitoring sampling point } \\
\text { (after } 30 \mathrm{~km} \text { of flow) }\end{array}$ & $73 \mathrm{CFU} / \mathrm{L}$ & $\begin{array}{l}60 \mathrm{CFU} / \mathrm{L} \\
10 \mathrm{CFU} / \mathrm{L} \\
3 \mathrm{CFU} / \mathrm{L}\end{array}$ & $\begin{array}{l}\text { Aaosphaeria } \\
\text { Cystobasidium } \\
\text { Exophiala }\end{array}$ & $\begin{array}{l}\text { arxii } \\
\text { lysinophilum } \\
\text { equina }\end{array}$ & $\begin{array}{c}14906,14907 \\
14905 \\
14908\end{array}$ \\
\hline
\end{tabular}

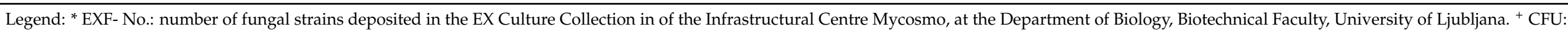
colony-forming units; fungal particles, spores, and conidia germinating in a new colony. 


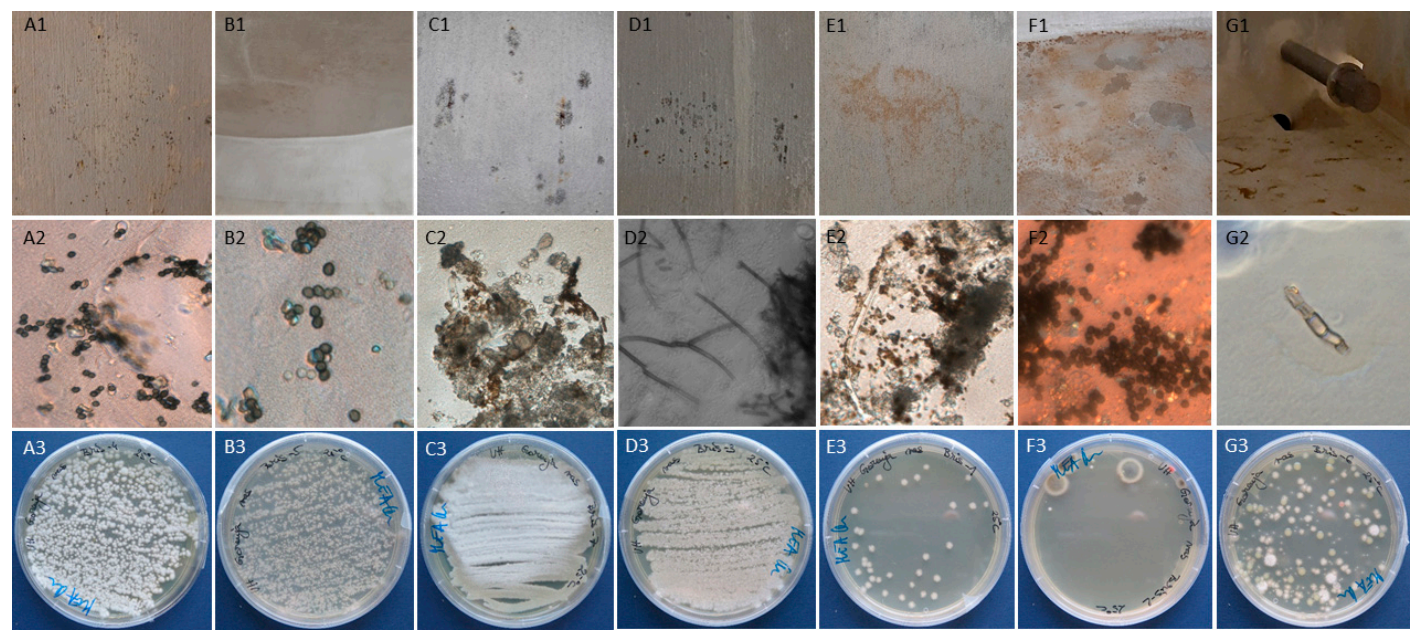

Figure 3. Presence of fungi inside concrete water storage tanks. Fungal growth with visible mycelia was observed as black and ochre colonies on concrete ceilings at the entrance (A1) and inside the cell (B1), on a dry wall (C1), humid wall (D1), and wet wall (E1). Samples were taken also from the bottom of the tank (F1) with visible peeling and change of the colour and from the metal pipe for water outflow (G1). (A2-G2): Microscopic observation of adhesive tape samples revealed diverse mycobiota producing brown conidia and brown to hyaline hyphae at all sampling sites. (A3-G3): Fungal colonies on MEA medium grown from swab samples taken from $1 \mathrm{~cm}^{2}$ surface.

\subsection{Oligotrophic and Aerophilic Conditions Promote Fungal Growth}

All tested strains incubated for a month at $15^{\circ} \mathrm{C}$ grew well on both oligotrophic media, YNB and WA, mimicking low-nutrient conditions inside water-networks and water storage tanks. However, their growth was slower on Xypex Concentrate plates, incubated at $15^{\circ} \mathrm{C}$ for 3 months. Only $40.4 \%$ of the strains grew weakly $(+), 13.5 \%$ grew poorly $(-/+)$, while $46.1 \%$ of the strains did not grow at these conditions (Table 2).

The growth of fungi at different aerobic conditions was determined by the immersion of the mycelium in liquid $\mathrm{pH}$ medium in glass tubes without shaking. Fifty percent of tested strains formed mycelium between the top to the middle of glass tubes, $32.7 \%$ strains grew throughout the whole medium column, and $17.3 \%$ grew from the middle to the bottom of the testing tubes (Table 2). These results are in accordance with the numbers and diversity of fungi isolated from water storage tanks. Most of these fungi grew better on well-aerated ceilings, upper and middle walls, while the lowest number was detected on the bottom of the retention tanks.

\subsection{Two-Thirds of Water-Related Strains Produce Acidic Metabolites}

Production of acidic or alkaline fungal metabolites can have a long-term effect on the biodeterioration of materials. Possible biodeterioration ability of isolated strains was tested in liquid medium with neutral $\mathrm{pH}$ and on solid medium with added calcium carbonate $\left(\mathrm{CaCO}_{3}\right)$ and glucose. After incubation in the $\mathrm{pH}$ medium, 32.7\% of strains were classified as producers of alkaline metabolites, since $\mathrm{pH}$ rose in a range of 0.01 to 0.5 units. On the other hand, $67.3 \%$ of tested strains acidified the medium, most of them (55.8\%) lowered $\mathrm{pH}$ in a range between 0.01 and 0.5 units and $3.8 \%$ lowered $\mathrm{pH}$ in a range of 0.5 to 1.5 units (Table 2). Penicillium strains (P. bialowiezense, P. brevicompactum, and P. glabrum; representing $7.7 \%$ ) were the best producers of acidic metabolites, lowering $\mathrm{pH}$ between 1.5 to 3.0 units. All these penicillia also actively dissolved calcium carbonate on solid plates, with a clearing zone appearing after incubation. Besides Penicillium, only four other strains (A. muscarius, Gloeotinia sp., N. fragariae, and T. versicolor) clearly dissolved calcium carbonate, shown as the formation of clearing zones (Table 2). Additionally, Gloeotinia sp. was the only strain that changed during growth on calcium carbonate the color of the mycelium from white-yellowish to ochre. 
Table 2. Representative fungal strains isolated from water storage tanks and drinking water, used to test the growth in vitro.

\begin{tabular}{|c|c|c|c|c|c|c|c|c|c|c|c|}
\hline \multirow{3}{*}{ Genus } & \multirow{3}{*}{ Species } & \multirow{3}{*}{ EXF-No. } & \multirow{3}{*}{ GenBank No. } & \multicolumn{7}{|c|}{ Growth after 1 Month } & \multirow{3}{*}{$\begin{array}{c}\text { Growth after } 3 \text { Months } \\
\text { Xypex Medium } \\
15^{\circ} \mathrm{C}\end{array}$} \\
\hline & & & & \multicolumn{2}{|c|}{$0.01 \times$ YNB } & \multirow{2}{*}{$\frac{2 \% \mathrm{WA}}{15^{\circ} \mathrm{C}}$} & \multicolumn{2}{|c|}{$\mathrm{CaCO}_{3}$ Medium } & \multicolumn{2}{|c|}{$\mathrm{pH}$ Medium } & \\
\hline & & & & $15^{\circ} \mathrm{C}$ & $37^{\circ} \mathrm{C}$ & & $15^{\circ} \mathrm{C}$ & Dissolution & pH Change & $\begin{array}{l}\text { Position of } \\
\text { Mycelium }\end{array}$ & \\
\hline Aaosphaeria & arxii & 14906 & MT178773 (ITS) & +++ & - & +++ & +++ & - & $\downarrow 0.41$ & throughout & - \\
\hline Acremonium & camptosporum & 14923 & MT178774 (ITS) & +++ & - & ++ & +++ & - & $\downarrow 0.15$ & top to middle & - \\
\hline Acremonium & charticola & 14755 & MT178775 (ITS) & ++ & - & +++ & ++ & - & $\downarrow 0.24$ & throughout & + \\
\hline Acremonium & sclerotigenum & $\begin{array}{l}14916 \\
14749\end{array}$ & $\begin{array}{l}\text { MT178776 (ITS) } \\
\text { MT178777 (ITS) }\end{array}$ & $\begin{array}{l}+++ \\
+++\end{array}$ & $\begin{array}{l}+++ \\
+++\end{array}$ & $\begin{array}{l}+++ \\
+++\end{array}$ & $\begin{array}{l}+++ \\
+++\end{array}$ & $\begin{array}{l}- \\
-\end{array}$ & $\begin{array}{l}\downarrow 0.22 \\
\downarrow 0.25\end{array}$ & $\begin{array}{l}\text { throughout } \\
\text { throughout }\end{array}$ & $\begin{array}{c}+ \\
-/+\end{array}$ \\
\hline Akanthomyces & muscarius & 14589 & MT178778 (ITS) & +++ & + & +++ & +++ & +++ & $\downarrow 0.40$ & top to middle & $-/+$ \\
\hline Aspergillus & protuberus & 14928 & MT178779 (ITS) & +++ & - & +++ & +++ & - & $\uparrow 0.36$ & top to middle & - \\
\hline Bjerkandera & adusta & 14740 & MT178780 (ITS) & +++ & $-/+$ & +++ & ++ & - & $\downarrow 0.15$ & bottom to middle & + \\
\hline Cadophora & malorum & $\begin{array}{l}14747 \\
14934\end{array}$ & $\begin{array}{l}\text { MT178781 (ITS) } \\
\text { MT178782 (ITS) }\end{array}$ & $\begin{array}{l}+++ \\
+++\end{array}$ & $\begin{array}{l}-/+ \\
-\end{array}$ & $\begin{array}{l}+++ \\
+++\end{array}$ & $\begin{array}{l}+++ \\
+++\end{array}$ & - & $\begin{array}{l}\downarrow 0.29 \\
\downarrow 0.33\end{array}$ & $\begin{array}{l}\text { top to middle } \\
\text { top to middle }\end{array}$ & $\begin{array}{l}- \\
+\end{array}$ \\
\hline Cladosporium & allicinum & $\begin{array}{l}14578 \\
14746 \\
14572\end{array}$ & $\begin{array}{l}\text { MT239332 (act) } \\
\text { MT239333 (act) } \\
\text { MT239331 (act) }\end{array}$ & $\begin{array}{l}+++ \\
+++ \\
+++\end{array}$ & $\begin{array}{l}- \\
- \\
-\end{array}$ & $\begin{array}{l}+++ \\
+++ \\
+++\end{array}$ & $\begin{array}{c}+++ \\
+ \\
+++\end{array}$ & $\begin{array}{l}- \\
- \\
-\end{array}$ & $\begin{array}{l}\downarrow 0.05 \\
\downarrow 0.12 \\
\uparrow 0.04\end{array}$ & $\begin{array}{c}\text { top to middle } \\
\text { bottom to middle } \\
\text { top }\end{array}$ & $\begin{array}{l}+ \\
+ \\
+\end{array}$ \\
\hline Cladosporium & halotolerans & $\begin{array}{l}14567 \\
14577 \\
\end{array}$ & $\begin{array}{l}\text { MT239334 (act) } \\
\text { MT239335 (act) }\end{array}$ & $\begin{array}{l}+++ \\
+++\end{array}$ & $\begin{array}{l}- \\
-\end{array}$ & $\begin{array}{l}+++ \\
+++\end{array}$ & $\begin{array}{l}+++ \\
+++\end{array}$ & $\begin{array}{l}- \\
-\end{array}$ & $\begin{array}{l}\uparrow 0.12 \\
\uparrow 0.07\end{array}$ & $\begin{array}{l}\text { throughout } \\
\text { throughout }\end{array}$ & $\begin{array}{l}+ \\
+ \\
\end{array}$ \\
\hline Cladosporium & perangustum & 14579 & MT239330 (act) & +++ & - & +++ & +++ & - & $\downarrow 0.34$ & top to middle & + \\
\hline Cladosporium & pseudocladosporioides & $\begin{array}{l}14566 \\
14745 \\
14924\end{array}$ & $\begin{array}{l}\text { MT239336 (act) } \\
\text { MT239337 (act) } \\
\text { MT239338 (act) }\end{array}$ & $\begin{array}{l}+++ \\
+++ \\
+++\end{array}$ & $\begin{array}{l}- \\
- \\
-\end{array}$ & $\begin{array}{l}+++ \\
+++ \\
+++\end{array}$ & $\begin{array}{l}+++ \\
+++ \\
+++\end{array}$ & $\begin{array}{l}- \\
- \\
-\end{array}$ & $\begin{array}{l}\uparrow 0.41 \\
\downarrow 0.04 \\
\uparrow 0.28\end{array}$ & $\begin{array}{l}\text { top } \\
\text { top } \\
\text { top }\end{array}$ & $\begin{array}{l}+ \\
+ \\
+\end{array}$ \\
\hline Cladosporium & sphaerospermum & $\begin{array}{l}14573 \\
14744 \\
14927\end{array}$ & $\begin{array}{l}\text { MT239340 (act) } \\
\text { MT239341 (act) } \\
\text { MT239342 (act) }\end{array}$ & $\begin{array}{l}+++ \\
+++ \\
+++\end{array}$ & $\begin{array}{l}- \\
- \\
-\end{array}$ & $\begin{array}{l}+++ \\
+++ \\
+++\end{array}$ & $\begin{array}{l}+++ \\
+++ \\
+++\end{array}$ & $\begin{array}{l}- \\
- \\
-\end{array}$ & $\begin{array}{l}\downarrow 0.21 \\
\downarrow 0.04 \\
\downarrow 0.07\end{array}$ & $\begin{array}{l}\text { top to middle } \\
\text { top to middle } \\
\text { top to middle }\end{array}$ & $\begin{array}{l}+ \\
- \\
+\end{array}$ \\
\hline Cystobasidium & lysinophilum & 14905 & MT154654 (LSU) & +++ & $-/+$ & ++ & + & - & $\uparrow 0.11$ & bottom & - \\
\hline Emericellopsis & sp. & 14936 & MT178783 (ITS) & +++ & - & +++ & ++ & - & $\downarrow 0.19$ & top to middle & + \\
\hline Epicoccum & nigrum & 14736 & MT178784 (ITS) & +++ & - & +++ & +++ & - & $\uparrow 0.05$ & bottom & + \\
\hline Exophiala & cancerae & 14903 & MT178785 (ITS) & +++ & - & +++ & +++ & - & $\uparrow 0.05$ & throughout & + \\
\hline Exophiala & equina & 14908 & MT178786 (ITS) & +++ & - & +++ & +++ & - & $\uparrow 0.07$ & throughout & + \\
\hline Filobasidium & uniguttulatum & 14741 & MT154655 (LSU) & +++ & + & ++ & ++ & - & $\downarrow 0.03$ & bottom & $-/+$ \\
\hline
\end{tabular}


Table 2. Cont.

\begin{tabular}{|c|c|c|c|c|c|c|c|c|c|c|c|}
\hline \multirow{3}{*}{ Genus } & \multirow{3}{*}{ Species } & \multirow{3}{*}{ EXF-No. } & \multirow{3}{*}{ GenBank No. } & \multicolumn{7}{|c|}{ Growth after 1 Month } & \multirow{3}{*}{$\begin{array}{c}\text { Growth after } 3 \text { Months } \\
\text { Xypex Medium } \\
15^{\circ} \mathrm{C}\end{array}$} \\
\hline & & & & \multicolumn{2}{|c|}{$0.01 \times$ YNB } & \multirow{2}{*}{$\frac{2 \% \text { WA }}{15^{\circ} \mathrm{C}}$} & \multicolumn{2}{|c|}{$\mathrm{CaCO}_{3}$ Medium } & \multicolumn{2}{|c|}{ pH Medium } & \\
\hline & & & & $15^{\circ} \mathrm{C}$ & $37^{\circ} \mathrm{C}$ & & $15^{\circ} \mathrm{C}$ & Dissolution & pH Change & $\begin{array}{l}\text { Position of } \\
\text { Mycelium }\end{array}$ & \\
\hline \multirow{2}{*}{ Furcasterigmium } & \multirow{2}{*}{ furcatum } & 14583 & MT178787 (ITS) & +++ & ++ & +++ & +++ & - & $\downarrow 0.14$ & throughout & - \\
\hline & & 14926 & MT178788 (ITS) & +++ & ++ & +++ & +++ & - & $\downarrow 0.11$ & throughout & - \\
\hline Gloeotinia & sp. & 14920 & MT178789 (ITS) & +++ & - & +++ & +++ & + & $\downarrow 0.50$ & throughout & - \\
\hline Keissleriella & caudata & 14921 & MT178792 (ITS) & +++ & - & +++ & +++ & - & $\uparrow 0.12$ & top to middle & - \\
\hline \multirow{2}{*}{ Musicillium } & \multirow{2}{*}{ elettariae } & 14922 & MT178793 (ITS) & +++ & $-/+$ & +++ & +++ & - & $\downarrow 0.21$ & throughout & $-/+$ \\
\hline & & 14931 & MT178794 (ITS) & +++ & $-1+$ & +++ & +++ & - & $\downarrow 0.11$ & throughout & $-1+$ \\
\hline Neopyrenochaeta & acicola & 14748 & MT178795 (ITS) & +++ & - & +++ & +++ & - & $\uparrow 0.36$ & bottom to middle & - \\
\hline \multirow{2}{*}{ Neopyrenochaeta } & \multirow{2}{*}{ fragariae } & 14737 & MT178797 (ITS) & ++ & - & + & +++ & +++ & $\downarrow 0.44$ & top & - \\
\hline & & 14754 & MT178796 (ITS) & +++ & - & ++ & +++ & - & $\uparrow 0.18$ & bottom to middle & - \\
\hline \multirow{2}{*}{ Paraphoma } & \multirow{2}{*}{ radicina } & 14933 & MT178799 (ITS) & +++ & - & +++ & +++ & - & $\downarrow 0.03$ & top & - \\
\hline & & 14904 & MT178798 (ITS) & +++ & - & ++ & +++ & - & $\downarrow 0.17$ & top & - \\
\hline Penicillium & bialowiezense & 14581 & MT162690 (benA) & +++ & - & +++ & +++ & +++ & $\downarrow 2.71$ & top to middle & - \\
\hline Penicillium & brevicompactum & 14919 & MT162692 (benA) & +++ & - & +++ & +++ & +++ & $\downarrow 1.66$ & top & - \\
\hline Penicillium & glabrum & 14569 & MT162693 (benA) & +++ & - & +++ & +++ & +++ & $\downarrow 2.18$ & top to middle & - \\
\hline Penicillium & verhagenii & 14571 & MT162694 (benA) & +++ & - & +++ & ++ & - & $\downarrow 0.33$ & top to middle & + \\
\hline \multirow{3}{*}{ Sarocladium } & \multirow{3}{*}{ kiliense } & 14582 & MT178800 (ITS) & +++ & ++ & +++ & +++ & - & $\uparrow 0.02$ & throughout & - \\
\hline & & 14930 & MT178801 (ITS) & +++ & ++ & +++ & +++ & - & $\uparrow 0.10$ & throughout & - \\
\hline & & 14935 & MT178802 (ITS) & +++ & ++ & +++ & +++ & - & $\uparrow 0.05$ & throughout & - \\
\hline Scopulariopsis & brumptii & 14743 & MT178803 (ITS) & +++ & - & +++ & ++ & - & $\uparrow 0.14$ & throughout & + \\
\hline Stereum & armeniacum & 14932 & MT178804 (ITS) & +++ & $-1+$ & ++ & - & - & $\downarrow 0.79$ & top & $-/+$ \\
\hline Trametes & versicolor & 14925 & MT178805 (ITS) & +++ & - & +++ & +++ & ++ & $\downarrow 1.34$ & bottom to middle & - \\
\hline
\end{tabular}

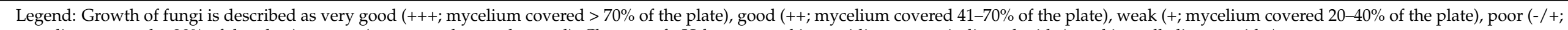
mycelium covered $<20 \%$ of the plate) or none (-; no growth was observed). Changes of $\mathrm{pH}$ from neutral into acidic zone are indicated with $\downarrow$, and into alkali zone with $\uparrow$. 


\subsection{Water-Borne Fungi and Possible Effect on Human Health}

The ability of fungal strains to grow at $37{ }^{\circ} \mathrm{C}$ is the most important virulence factor for possible colonization of the human body [8]. Thermotolerant potential of representative strains was thus tested on solid plates with 100 -times diluted $\mathrm{YNB}$, incubated at $37^{\circ} \mathrm{C}$ for 1 month. After incubation, $5.8 \%$ of the strains expressed very good $(+++)$ growth, $9.6 \%$ good growth (++), and 3.8\% weak growth (+). Poor growth was observed for $11.5 \%$ of the strains, while $69.3 \%$ of the strains did not grow at this temperature at all (Table 2). Best growth was observed for A. sclerotigenum and Moesziomyces aphidis, followed by F. furcatum and S. kiliense.

\section{Discussion}

Preparation of drinking water in EU countries depends on the availability of the main water source and is strictly monitored as requested by Drinking Water Directive (98/83/EC) [5]. Predominant geological structures within the territory of Slovenia are sedimentary rocks and sediment deposits, which are ideal for the development of aquifers [29]. Due to the favorable geological location and relatively easy access, groundwater is the main raw water source in Slovenia. In total, $85 \%$ of the country's population drinking water is supplied with groundwater, and only $3 \%$ of the population uses surface or rainwater. The rest use water from their own wells [30,31]. The geological specialty of Slovenia is the karst system, covering $>44 \%$ of the territory [29]. Underground karstic aquifers occur due to their limestone structure and thin layers that are very sensitive to anthropogenic pollution that may affect water quality [30]. To meet the microbiological criteria set in Drinking Water Directive (98/83/EC), out of 866 active Slovenian water supply areas (WS), 31\% do not need disinfection for water preparation, $9 \%$ use disinfection procedures occasionally, and $60 \%$ have permanent disinfection [31]. Similar to other countries, the most common chemical disinfection process in Slovenia is chlorination with sodium hypochlorite $(\mathrm{NaOCl})$, chlorine gas $\left(\mathrm{Cl}_{2}\right)$, and chlorine dioxide $\left(\mathrm{ClO}_{2}\right)$, being used in $40 \%, 14.1 \%$ and $2.2 \%$ of water supplies, respectively. During the last years also use of non-chemical UV disinfection increased [31].

Drinking water samples analyzed in the study were obtained from the karst area where the raw water source originates as groundwater below thin layers of limestone. The water supply company has installed a modern system of pre-treatment with combined ultrafiltration and disinfection with chlorine gas. Additionally, new ground concrete reservoirs for water storage and distribution have been built. However, after 1.5 years of regular use, cement coatings inside concrete water storage tanks showed changes in color from white to ochre, with sporadically observed local peelings. Additionally, also visible is contamination resembling mold colonies appeared on the upper ceilings and walls. Nevertheless, all microbiological and chemical parameters measured for the regular drinking water monitoring were within the normal range as set in Drinking Water Directive (98/83/EC) [5]. The reasons for following the occurrence and diversity of fungi were (i) possible impact on material degradation and (ii) possible impact on consumers' health.

In order to find out whether fungi caused discoloration, peeling and visible contamination of upper ceilings and walls, six different surface spots inside the two water retention tanks filled with drinking water of the same origin were sampled. Together 12 sampling spots of the tanks' surface were sampled. Additionally, samples of drinking water were taken from eight points throughout the water network system to follow related fungal contamination. All samples of drinking water and storage tanks were positive for fungi. Since there is currently no uniform parametric value for fungi in drinking water, we compared our results with the Swedish legislation [32], which limits the presence of fungi to $100 \mathrm{CFU}$ per $100 \mathrm{~mL}$ (equivalent to $1000 \mathrm{CFU} / \mathrm{L}$ ). None of the samples exceeded this number. However, the highest number estimated as $\sim 637 \mathrm{CFU} / \mathrm{L}$ and diversity of fungi were determined in water at the entrance of water storage tanks, after being transported from the Water Company through the old system constructed of iron-based pipes. The reason for the high number of fungi could be their presence in well-established biofilms 
inside the old pipes $[13,33]$. Their number lowered already at the outflow of the water storage tanks and was the lowest at both consumers' endpoints. The lowered counts are likely due to chlorination since residual chlorine was present throughout the entire system [34-36]. Although mycobiota differed between the sampling locations, isolated species of the genera Acremonium, Cadophora, Cladosporium, Epicoccum, Penicillium and Rhodotorula represented the "core-species", as described previously in other EU countries, confirming drinking water as an important vector for their transmission $[4,6,8]$. These fungal genera are also common in surface water or water from karst systems with thin layers of sediments [4,37]. Surprisingly, we did not isolate Aspergillus, Aureobasidium, or Candida species, which otherwise represent dominant groups of fungi in groundwater-derived drinking water in Slovenia [38]. The reason could be their susceptibility to chlorination [34-36,39,40] or the mixed source of water as is common in karstic systems. We additionally successfully isolated yeasts belonging to the genera Cystobasidium, Filobasidium, Moesziomyces and Rhodotorula. The ratio between isolated yeasts vs. filamentous fungi was 1:29 in favor of the filamentous fungi, in accordance with studies of biofilms in drinking water distribution systems [33,41]. Despite relatively high numbers of different fungi in the entering water, only Acremonium, Cadophora, Cladosporium, and Paraphoma were isolated from both waters, and the surfaces of water storage tanks. Since sampling was performed only once as a case study, the reasons for a limited number of species found on both surfaces and drinking water may be the fluctuation in mycobiota in the water at the time of the sampling [42].

Main pipes, large retention centres and modern water storage tanks are made of rough concrete covered with coatings to prevent leaching and corrosion of metals used in concrete [19]. After the relative humidity of the material in constant contact with water raises above $80 \%$ it represents an ideal scaffold for secondary colonizers like Aspergillus flavus, A. versicolor, Cladosporium cladosporioides, C. herbarum, C. sphaerospermum, Mucor circinelloides and Rhizopus oryzae [14]. With relative humidity above $90 \%$, wet material promotes the growth of a variety of water-related hydrophilic species [14]. Another important factor affecting the growth of fungi on wet materials is the presence of oxygen. Most fungi are aerobes, some are microaerophilic, but both groups need oxygen for the synthesis of cell membrane constituents, like ergosterol and unsaturated fatty acids. Additionally, oxygen is needed in the respiratory chain as the terminal electron acceptor [43]. Considering both, the high relative humidity and fungal need for oxygen, it can be expected that fungi would more likely colonize ceilings and upper humid walls of concrete water storage tanks. Wet concrete and finishing materials thus often harbor the genera Acremonium, Cladosporium, Aspergillus, Bjerkandera, Sporothrix, Chaetomium, Mucor, Stachybotrys, Ulocladium, Phoma and Penicillium. Yeasts on concrete are less diverse and belong mainly to the genera Candida, Debaryomyces, Kluyveromyces, Meyerozyma and Rhodotorula $[15,16]$. Our results, both in diversity and numbers of fungi, are in accordance with previous studies, with Aspegillus, Cladosporium, and Sarocladium, Furcasterigmium and Musicillium (all previously described as Acremonium) being the most common. Their numbers were highest on well-aerated dry ceilings and upper walls with locally visible condensate and lower on humid walls and walls constantly under water level (Table 1 ). The need for oxygen was confirmed with the test in liquid medium without shaking. Species of Akanthomyces, Aspergillus and Cladosporium, found on upper ceilings and walls of storage tanks grew only on the top of the medium. On the contrary, Musicillium, Sarocladium and Furcasterigmium, isolated from dry and humid walls, as well as from the walls under constant water level, grew throughout the whole medium column, from totally aerobic to microaerophilic conditions (Table 2).

After a prolonged time of use, materials react with chemical components and disinfectants in water and become more susceptible to biofilm formation and biodegradation $[1,8]$. The presence and growth of fungi in water and on concrete may affect the material via the production of organic acids $[17,18]$ causing local scaling. The process often involves Aspergillus, Penicillium, Fusarium, Paecilomyces, Talaromyces, Stachybotrys, and zygomycetous fungi $[15,44]$. The opposite process, known as "self-healing concrete", was confirmed for 
Trichoderma reesei and Candida tropicalis and starts with the dissolution of $\mathrm{Ca}(\mathrm{OH})_{2}$, leading to the precipitation of calcite on the surface of fungal cells [44,45]. Production of acidic or alkaline products of isolated fungal strains was tested in liquid medium with neutral $\mathrm{pH}$. Two-thirds of tested strains produced acidic metabolites, with the genus Penicillium being able to lower $\mathrm{pH}$ up to three units (Table 2). These strains also displayed the largest clearing zones on the solid medium with added calcium carbonate $\left(\mathrm{CaCO}_{3}\right)$ and glucose, while among other producers of acidic compounds only four strains additionally dissolved $\mathrm{CaCO}_{3}$ (Table 2), indicating additional mechanisms, besides acid production, affecting the solubility of calcium carbonate. Among isolated strains, only Gloeotinia sp. produced acidic metabolites, dissolved calcium carbonate, and changed the color of mycelium from white-yellowish to ochre.

Following chemical dissolution, hypothetically, in-depth growth of hyphae causes mechanical degradation of the material [19], as described for water-related genera $\mathrm{Al}$ ternaria, Aspergillus, Cephalosporium, Cladosporium, Mucor, Penicillium, Rhizopus, and Trichoderma $[44,46]$. When using Xypex Concentrate as the only source of nutrients, only $40.4 \%$ of the strains showed weak growth, seen as thin mycelium on the surface of the plates. Since the test was carried out only for 3 months, with single strains under highly oligotrophic conditions, these fungi nevertheless showed the potential for biomechanical degradation, particularly over a prolonged time, in an environment contaminated with a mixed biofilm and in the presence of additional nutrients carried by water.

Although the presence of fungi can induce, as side effects, chemical dissolution and mechanical degradation of material, observed as changes of odor and taste of drinking water, these changes alone do not pose danger to human health $[8,47]$. One of the main worries is the potentially elevated number of opportunistic and/or mycotoxigenic fungi. Fungal ability to colonize the human body does not depend on fungal physiology only, but greatly also on the immune defense of the host [48] and the ability of strains to grow at $37^{\circ} \mathrm{C}$. In the case of tested strains from drinking water and storage tanks, $29.7 \%$ grew at $37^{\circ} \mathrm{C}$, and only $7.7 \%$ were classified under Biosafety Level 2 (e.g., Sarocladium kiliense and Filobasidium uniguttulatum). However, none of them was detected at consumers' taps, indicating a low risk for fungal infections through the sampled water.

Mycotoxins are well described in agriculture and food production, but there are still few data about mycotoxins in water. One of the issues may be their detection and quantification, because only a few are hydrophilic (e.g., fumonisins), while most known toxins are hydrophobic [49]. Chlorination inactivates some mycotoxins (e.g., aflatoxin B1), and recent studies reported low levels of mycotoxins in European chlorinated water, but the caution must be maintained in cases of low- or unchlorinated water, particularly when drawn from surface water sources or water sources of mixed origin $[6,50,51]$.

\section{Conclusions}

Building materials in contact with drinking water must be, on one hand, safe for use, and on the other hand, able to sustain quick degradation processes. Yet, many chemical and biological agents present in nature can fasten their degradation. We investigated the presence of fungi, known degraders of recalcitrant materials, inside affected modern concrete water storage tanks. The tanks were filled with chlorinated drinking water originating from a karstic water source. The majority of isolated fungi were able to grow under water level, produced acids and dissolved carbonate media, thus fungi should be taken into consideration also as causative agents of visible coloration and peeling of retention tank surfaces in contact with drinking water. Fungal abundance, followed from storage tanks throughout the distribution system, gradually diminished and was the lowest at consumers' taps. No known opportunistic pathogens were detected, yet they need to be taken into consideration in cases with visible overgrowth of mycelia inside retention tanks.

Author Contributions: M.N.B. designed and performed the study and wrote the manuscript; N.G.-C. supervised the process and reviewed the manuscript. All authors have read and agreed to the published version of the manuscript. 
Funding: The work of Dr. Monika Novak Babič was financed by Slovenian Research Agency (ARRS), through the postdoctoral project Z7-2668 and under the programme number P1-0198.

Institutional Review Board Statement: Not Applicable.

Informed Consent Statement: Not Applicable.

Data Availability Statement: Not Applicable.

Acknowledgments: We thank to the personnel of the Water Company Komunala Novo mesto d.o.o. for their kind assistance during the sampling and for performing physico-chemical analyses of water. We also thank to the personnel from the Department of Materials, Slovenian National Building and Civil Engineering Institute for providing Xypex Concentrate.

Conflicts of Interest: The authors declare no conflict of interest. The funders had no role in the design of the study; in the collection, analyses, or interpretation of data; in the writing of the manuscript, or in the decision to publish the results.

\section{References}

1. Gray, F.N. Pathogen control in drinking water. In Microbiology of Waterborne Diseases, 2nd ed.; Percival, L.S., Yates, V.M., Eds.; Elsevier: Oxford, UK, 2014; pp. 537-570.

2. Percival, L.S.; Yates, V.M.; Williams, W.D.; Chalmers, R.M.; Gray, F.N. Microbiology of Waterborne Diseases, 2nd ed.; Elsevier: Oxford, UK, 2014.

3. Handmer, J.; Honda, Y.; Kundzewicz, Z.W.; Arnell, N.; Benito, G.; Benito, G.; Hatfield, J.; Mohamed, I.F.; Peduzzi, P.; Wu, S.; et al. Changes in impacts of climate extremes: Human systems and ecosystems. In Managing the Risks of Extreme Events and Disasters to Advance Climate Change Adaptation. A Special Report of Working Groups 1 and 2 of the Intergovernmental Panel on Climate Change (IPCC); Field, C.B., Barros, V., Stocker, T.F., Dahe, Q., Eds.; Cambridge University Press: Cambridge, UK; New York, NY, USA, 2012; pp. 231-290.

4. Novak Babič, M.; Gunde-Cimerman, N.; Vargha, M.; Tischner, Z.; Magyar, D.; Veríssimo, C.; Sabino, R.; Viegas, C.; Meyer, W.; Brandão, J. Fungal contaminants in drinking water regulation? A tale of ecology, exposure, purification and clinical relevance. Int. J. Environ. Res. Public Health 2017, 14, 636. [CrossRef]

5. EEC. Council directive $98 / 83 / \mathrm{EC}$ on the quality of water intended for human consumption. Off. J. Eur. Communities 1998, $330,32-54$.

6. Novak Babič, M.; Brandão, J.; Gunde-Cimerman, N. Integrating Fungi in the Drinking Water Regulation and in Guidelines for Materials in Contact with Drinking Water. Is there Room for Change? In Reference Module in Life Sciences; Elsevier: Amsterdam, The Netherlands, 2020. [CrossRef]

7. Friedman, D.Z.P.; Schwartz, I.S. Emerging Fungal Infections: New Patients, New Patterns, and New Pathogens. J. Fungi 2019, 5, 67. [CrossRef] [PubMed]

8. DEFRA (Department for Environment, Food \& Rural Affairs). A Review of Fungi in Drinking Water and the Implications for Human Health, 1st ed.; BIO Intelligence Service: Paris, France, 2011; p. 107.

9. Novak Babič, M.; Zupančič, J.; Brandão, J.; Gunde-Cimerman, N. Opportunistic water-borne human pathogenic filamentous fungi unreported from food. Microorganisms 2018, 6, 79. [CrossRef] [PubMed]

10. 4MS. Acceptance of Metallic Materials Used for Products in Contact with Drinking Water, 1st ed.; 4MS Joint Management Comitee, Germany, France; The Netherlands and United Kingdom: Berlin, Germany, 2011.

11. NLZOH; ZAG; NIJZ. Priporočila za Ocenjevanje Primernosti Materialov in Proizvodov, ki Prihajajo v Stik s Pitno Vodo in So del Vodovodnega Omrežja in Interne Vodovodne Napeljave (P-MPPV), 1st ed.; Nacionalni Laboratorij za Zdravje, Okolje in Hrano: Maribor, Slovenia; Zavod za Gradbeništvo Slovenije: Ljubljana, Slovenia; Nacionalni Inštitut za Javno Zdravje: Ljubljana, Slovenia, 2016.

12. Douterelo, I.; Jackson, M.; Solomon, C.; Boxall, J. Microbial analysis of in situ biofilm formation in drinking water distribution systems: Implications for monitoring and control of drinking water quality. Appl. Microbiol. Biotechnol. 2016, 100, 3301-3311. [CrossRef] [PubMed]

13. Liu, L.; Liu, Y.; Lu, Q.; Chen, G.; Wang, G. Assessing comprehensive performance of biofilm formation and water quality in drinking water distribution systems. Water Sci. Technol. 2017, 17, 267-278. [CrossRef]

14. WHO. Guidelines for Indoor Air Quality: Dampness and Mould, 1st ed.; World Health Organization, Regional Office for Europe: Copenhagen, Denmark, 2009.

15. Andersen, B.; Frisvad, J.C.; Søndergaard, I.; Rasmussen, I.S.; Larsen, L.S. Associations between fungal species and water-damaged building materials. Appl. Environ. Microbiol. 2011, 77, 4180-4188. [CrossRef] [PubMed]

16. Hurtado-McCormick, S.; Sánchez, L.; Martínez, J.; Calderón, C.; Calvo, D.; Narváez, D.; Lemus, M.; Groot, H.; Rodríguez Susa, M. Fungi in biofilms of a drinking water network: Occurrence, diversity and mycotoxins approach. Water Supply 2016, 16, 905-914. [CrossRef] 
17. Hyde, K.D.; Xu, J.; Rapior, S.; Jeewon, R.; Lumyong, S.; Niego, A.G.T.; Abeywickrama, P.D.; Aluthmuhandiram, J.V.S.; Brahamanage, R.S.; Brooks, S.; et al. The amazing potential of fungi: 50 ways we can exploit fungi industrially. Fungal Divers. 2019, 97, 1-136. [CrossRef]

18. Dighton, J.; White, J. The Fungal Community: Its Organization and Role in the Ecosystem, 4th ed.; CRC Press, Taylor \& Francis Group: Florida, FL, USA, 2017.

19. Bertron, A. Understanding interactions between cementitious materials and microorganisms: A key to sustainable and safe concrete structures in various contexts. Mater. Struct. 2014, 47, 1787-1806. [CrossRef]

20. Van den Ende, A.H.G.; de Hoog, G.S. Variability and molecular diagnostics of the neurotropic species Cladophialophora bantiana. Stud. Mycol. 1999, 43, 151-162.

21. White, T.J.; Bruns, T.; Lee, S.; Taylor, J. Amplification and direct sequencing of fungal ribosomal RNA genes for phylogenetics. In PCR Protocols: A Guide to Methods and Applications; Innis, M.A., Gelfand, D.H., Sninsky, J.J., White, T.J., Eds.; Academic Press: San Diego, CA, USA, 1990; pp. 315-322.

22. Glass, N.; Donaldson, G. Development of primer sets designed for use with the PCR to amplify conserved genes from filamentous ascomycetes. Appl. Environ. Microbiol. 1995, 61, 1323-1330. [CrossRef] [PubMed]

23. Carbone, I.; Kohn, L.M. A method for designing primer sets for speciation studies in filamentous ascomycetes. Mycologia 1999, 91, 553-556. [CrossRef]

24. Boekhout, T.; Kurtzman, C.P. Principles and methods used in yeast classification, and an overview of currently accepted yeast genera. In Nonconventional Yeasts in Biotechnology; Wolf, K., Ed.; Springer: Berlin, Germany, 1996; pp. 1-81.

25. Kumar, S.; Stecher, G.; Tamura, K. MEGA7: Molecular Evolutionary Genetics Analysis version 7.0 for bigger datasets. Mol. Biol. Evolut. 2016, 33, 1870-1874. [CrossRef] [PubMed]

26. Altschul, S.F.; Gish, W.; Miller, W.; Myers, E.W.; Lipman, D.J. Basic local alignment search tool. J. Mol. Biol. 1990, 215 , 403-410. [CrossRef]

27. Albertano, P.; Urzì, C. Structural interactions among epi-lithic cyanobacteria and heterotrophic microorganisms in Romanhypogea. Microb. Ecol. 1999, 38, 244-252. [CrossRef]

28. Borrego, S.; Guiamet, P.; Gómez de Saravia, S.; Battistoni, P.; Garcia, M.; Lavin, P.; Perdomo, I. The quality of air at archives and the biodeterioration of photographs. Int. Biodeterior. Biodegrad. 2010, 64, 139-145. [CrossRef]

29. Hajna, N.Z.; Bosák, P.; Pruner, P.; Mihevc, A.; Hercman, H.; Horáček, I. Karst sediments in Slovenia: Plio-Quaternary multi-proxy records. Quat. Int. 2020, 546, 4-19. [CrossRef]

30. Government of the Republic of Slovenia. Načrt Upravljanja Voda na Vodnem Območju Donave za Obdobje 2016-2021, 1st ed.; Vlada RS: Ljubljana, Slovenia, 2016; p. 295.

31. NLZOH. Monitoring Pitne Vode 2017—Letno Poročilo o Kakovosti Pitne Vode v Letu 2017; Nacionalni Laboratorij za Zdravje, Okolje in Hrano: Maribor, Slovenija; Ministrstvo za Zdravje: Ljubljana, Slovenija, 2017; p. 59.

32. NFA. Livsmedelsverkets Föreskrifter om Dricksvatten, SLVFS 2001:30, 1st ed.; National Food Administration: Uppsala, Sweden, 2001.

33. Douterelo, I.; Fish, K.E.; Boxall, J.B. Succession of bacterial and fungal communities within biofilms of a chlorinated drinking water distribution system. Water Res. 2018, 141, 74-85. [CrossRef]

34. Théraud, M.; Bédouin, Y.; Guiguen, C.; Gangneux, J.P. Efficacy of antiseptics and disinfectants on clinical and environmental yeast isolates in planktonic and biofilm conditions. J. Med. Microbiol. 2004, 53, 1013-1018. [CrossRef]

35. Sisti, M.; Brandi, G.; De Santi, M.; Rinaldi, L.; Schiavano, G.F. Disinfection efficacy of chlorine and peracetic acid alone or in combination against Aspergillus spp. and Candida albicans in drinking water. J. Water Health 2012, 10, 11-19. [CrossRef] [PubMed]

36. Pereira, V.J.; Marques, R.; Marques, M.; Benoliel, M.J.; Barreto Crespo, M.T. Free chlorine inactivation of fungi in drinking water sources. Water Res. 2013, 47, 517-523. [CrossRef] [PubMed]

37. Pereira, V.J.; Fernandes, D.; Carvalho, G.; Benoliel, M.J.; San Romão, M.V.; Crespo, M.B. Assessment of the presence and dynamics of fungi in drinking water sources using cultural and molecular methods. Water Res. 2010, 44, 4850-4859. [CrossRef] [PubMed]

38. Novak Babič, M.; Zalar, P.; Ženko, B.; Džeroski, S.; Gunde-Cimerman, N. Yeasts and yeast-like fungi in tap water and groundwater, and their transmission to household appliances. Fungal Ecol. 2016, 20, 30-39. [CrossRef]

39. Araujo, R.; Gonçalves Rodrigues, A.; Pina-Vaz, C. Susceptibility pattern among pathogenic species of Aspergillus to physical and chemical treatments. Med. Mycol. 2006, 44, 439-443. [CrossRef] [PubMed]

40. Mattei, A.S.; Madrid, I.M.; Santin, R.; Schuch, L.F.; Meireles, M.C. In vitro activity of disinfectants against Aspergillus spp. Braz. J. Microbiol. 2013, 44, 481-484. [CrossRef] [PubMed]

41. Grabińska-Łoniewska, A.; Konillowicz-Kowalska, T.; Wardzynska, G.; Boryn, K. Occurrence of fungi in water distribution system. Pol. J. Environ. Stud. 2007, 16, 539-547.

42. Urooj, S.; Mirani, Z.A.; Naz, S. Impact of Seasonal Variations on Bacterial, Yeast and Mold's Count in Drinking Water Collected from Karachi Pakistan. PSM Microbiol. 2018, 3, 37-42.

43. Walker, G.M.; White, N.A. Introduction to Fungal Physiology. In Fungi: Biology and Applications, 3rd ed.; Kavanagh, K., Ed.; John Wiley \& Sons, Inc.: New Jersey, NJ, USA, 2017; pp. 1-35.

44. Luo, J.; Chen, X.; Crump, J.; Zhou, H.; Davies, G.D.; Zhou, G.; Zhang, N.; Jin, C. Interactions of fungi with concrete: Significant importance for bio-based self-healing concrete. Constr. Build. Mater. 2018, 164, 275-285. [CrossRef]

45. Menon, R.R.; Luo, J.; Chen, X.; Zhou, H.; Liu, Z.; Zhou, G.; Zhang, N.; Jin, C. Screening of fungi for potential application of self-healing concrete. Sci. Rep. 2019, 9, 2075. [CrossRef] 
46. Shinkafi, S.A.; Haruna, I. Microorganisms associated with deteriorated desurface painted concrete buildings within Sokoto, Nigeria. Int. J. Curr. Microbiol. Appl. Sci. 2013, 2, 314-324.

47. WHO. Guidelines for Drinking Water Quality, 4th ed.; World Health Organization: Geneva, Switzerland, 2011.

48. de Hoog, G.S.; Guarro, J.; Gené, J.; Ahmed, S.; Al-Hatmi, A.M.S.; Figueras, M.J.; Vitale, R.G. Atlas of Clinical Fungi; Westerdijk Fungal Biodiversity Institute: Utrecht, The Netherlands, 2019.

49. Bennett, J.W.; Klich, M. Mycotoxins. Clin. Microbiol. Rev. 2003, 16, 497-516. [CrossRef] [PubMed]

50. Mata, A.T.; Ferreira, J.P.; Oliveira, B.R.; Batoréu, M.C.; Crespo, M.B.; Pereira, V.J.; Bronze, M.R. Bottled water: Analysis of mycotoxins by LC-MS/MS. Food Chem. 2015, 176, 455-464. [CrossRef] [PubMed]

51. Novak Babič, M.; Gostinčar, C.; Gunde-Cimerman, N. Microorganisms populating the water-related indoor biome. Appl. Microbiol. Biotechnol. 2020, 104, 6443-6462. [CrossRef] 